\title{
Visibilidade comprometida? A posição editorial dos jornais O Estado de São Paulo, Folha de São Paulo e O Globo a respeito do Escola Sem Partido
}

\begin{abstract}
Alexandro Kichileski ${ }^{1}$
Carlos Augusto Locatelli²

Resumo

$\mathrm{O}$ artigo enquadra e reflete as posições editoriais lançadas pelos jornais $O$ Estado de São Paulo, Folha de São Paulo e $O$ Globo a respeito do movimento Escola Sem Partido. Entendendo a esfera pública como espaço de discussão de cidadãos sobre o que é coletivo, a teoria deliberacionista reconhece o papel dos meios de comunicação de massa como fomentadores de visibilidade, crucial para o processo de discutibilidade e produção de consensos. O processo educativo é um tema de ordem pública com recorrentes discussões nas sociedades modernas. A partir de contribuições de análise crítica do discurso, recapitulação sobre ideologia e pressupostos de enquadramento o texto procura responder duas questões cardeais: Qual consenso é gerado pelos jornais? Esse consenso faz jus a complexidade do tema colaborando na construção do seu debate?
\end{abstract}

\section{Palavras-chaves}

Deliberacionismo; Escola Sem Partido; Editorial.

\begin{abstract}
The article fits in and reflects the editorial positions launched by the newspapers $O$ Estado de São Paulo, Folha de São Paulo and O Globo regarding the Escola Sem Partido movement. Understanding the public sphere as a space for citizens to discuss what is collective, deliberationist theory recognizes the role of the mass media as visibility promoters, crucial for the process of debate and consensus building. The educational process is a public order issue with recurrent discussions in modern societies. From contributions of critical discourse analysis, recapitulation on ideology and framing assumptions, the text seeks to answer two cardinal questions: What consensus is generated by the newspapers? Does this consensus live up to the complexity of the theme collaborating in the construction of your debate?
\end{abstract}

Keywords

Deliberationism; Escola Sem Partido; Editorial.

\footnotetext{
${ }^{1}$ Mestrando no Programa de Pós-Graduação em Jornalismo da Universidade Federal de Santa Catarina. alexandrokichileski@gmail.com

2 Doutor em Comunicação e Informação pela Universidade Federal do Rio Grande do Sul. Professor adjunto do Departamento de Jornalismo da Universidade Federal de Santa Catarina. locatelli.jor@gmail.com
} 


\section{VOZES $_{\text {\&IÁLORO }}^{\mid}$}

Itajaí, v. 18, n. 02, jul/dez 2019

\section{Introdução}

A esfera pública enquanto categoria central é definida como uma realidade concreta e representada por um ideal normativo. Entendida como esfera de pessoas privadas reunidas em público para discutir assuntos de interesse geral. Com um público heterogêneo, caracteriza-se por traços potencialmente abstrato na formação e circulação de opiniões. Também vista como uma engrenagem social, voltada para a solução coletiva dos problemas que afetam a sociedade civil em contraste com as pressões do sistema político e do Estado (GOMES, 2008), a esfera pública oferece legitimidade democrática ao poder exercido pelo Estado. Espera-se que essa esfera cultive o espírito deliberativo, procurando utilizar a razão (logos) na construção de argumentos sólidos para o entendimento mútuo. Os argumentos devem ser apresentados, questionados, aceitos ou refutados, legitimando o consenso que se produz em meio a negociação de significados e sentidos constituídas pelos participantes (HABERMAS, 2003).

Indiscutivelmente a educação é um dos temas mais recorrentes na esfera pública, levando em conta sua essencialidade para a constituição do próprio humano em sua humanidade. Pode-se refletir sobre a educação a partir de diversos ângulos: sejam pelos seus aspectos exteriores de manutenção da própria sociedade (DURKHEIM, 2011), pelos aspectos de subjetividade e criatividade que é imanente ao ser humano (LOBROT, 1992), ou ainda como meio rigoroso capaz de fomentar a racionalidade ética capaz de evitar a barbárie (ADORNO, 1995). Na modernidade, a aposta na educação formal e a universalização das instituições escolares tornaram-se preocupação central em todos os países. As políticas públicas em educação devem abarcar o educando em sua integralidade.

No Brasil a abertura democrática gerou bastante otimismo em relação a precária educação pública. As disputas por projetos educacionais evidenciam-se na elaboração da Constituição Federal de 1998 estendendo até a tramitação da Lei de Diretrizes e Bases da Educação Nacional (LDB) que foi concluída em 1996 (ARANHA, 2005). No entanto, na última década, aqueles que estavam descontentes com os rumos educacionais do país aglutinaram-se em um movimento chamado Escola Sem Partido (ESP). O movimento argumenta que, sob o pretexto de transmitir aos alunos uma visão crítica, os professores tornaram-se um exército organizado de militantes. Sua liberdade de cátedra virou uma cortina para imporem sua própria visão de mundo (ESCOLA SEM PARTIDO, 2009).

Reconhecendo a educação como assunto de interesse público e partindo do pressuposto de que os meios de comunicação de massa são essenciais na visibilidade (GOMES, 2008), imprescindíveis e norteadores da qualidade da discutibilidade, o presente texto procura evidenciar a produção de consenso dos editoriais de três jornais tradicionais no país: Folha de São Paulo, Estado de São Paulo e O Globo. Consenso esse em torno da proposta e ação política do movimento ESP. 


\section{VOZES $_{\text {\&DÁLORO }}^{\mid}$}

Itajaí, v. 18, n. 02, jul/dez 2019

A escolha por Editoriais se dá por reconhecer no gênero a forma mais transparente de conhecer o posicionamento oficial da empresa jornalística a respeito do assunto discutido. O primeiro editorial a abordar a ESP foi feito pela Folha de São Paulo foi intitulado "Na Base da Ideologia” publicado dia 15/05/2016. Já O Estado de São Paulo publicou seu primeiro editorial sobre o tema no dia 19/07/2016, chamado de "Ideologia na Escola”. Por fim, O Globo produziu seu texto "Um ensino Livre" no dia 15/07/2016. A partir do suporte teórico e dos argumentos editoriais espera-se elucidar ao menos duas questões no que se refere a ESP: Qual é o consenso gerado pelos editoriais dos três jornais? Esse consenso faz jus a complexidade do tema, colaborando na construção do seu debate?

\section{Do mundo da vida à opinião pública}

Termo esboçado pelo filósofo Edmund Hursserl, o mundo da vida é inicialmente compreendido como o amplo espaço das experiências e certezas précategoriais, relações intersubjetivas e valores comungados no cotidiano dos homens. Não se trata de uma atitude meramente natural, mas um mundo histórico cultural concreto das vivências e costumes que se encontram antes da sistematização científica. Habermas resgatará o conceito, tendo como ponto de partida que o conhecimento e o entendimento dos seres humanos são construídos através da intersubjetividade, compreendendo o mundo da vida como um bloco com modelos consentidos de interpretação e práticas, um pano de fundo para o agir comunicativo ${ }^{3}$ (PIZZI, 2006). O agir comunicativo vai pressupor a linguagem como suporte viabilizador do entendimento, instrumentos para atingir consenso.

Diferente do mundo da vida, o sistema é compreendido como ação deslinguistizada, ou seja, a linguagem ao perder o caráter de integração social torna-se uma simples fonte para transmitir a informação a um fim determinado que será alcançado por meios adequados, seja o dinheiro representando a economia ou o poder administrativo do Estado (PIZZI, 2006). O sistema do Estado e do mercado têm como lócus a racionalidade instrumental. $\mathrm{O}$ grande problema da modernidade, detectado pelo Habermas, é a

${ }^{3}$ Tão logo, porém, as forças ilocucionárias das ações de fala assumem um papel coordenador na ação, a própria linguagem passa a ser explorada como fonte primária da integração social. É isso que consiste o "agir comunicativo". Neste caso, os atores, na qualidade de falantes e ouvintes, tentam negociar interpretações comuns da situação e harmonizar entre si os seus respectivos planos através de processos de entendimento, portanto, pelo caminho de uma busca incondicionada de fins ilocucionários. Quando os participantes aprendem o enfoque objetivador de um observador e de um agente interessado imediatamente no próprio sucesso e passam a adotar um enfoque performativo falante que deseja entender-se com uma segunda pessoa sobre algo no mundo, as energias de ligação da linguagem podem ser mobilizadas para a coordenação de planos de ação. Sob essa condição, ofertas de atos de fala podem visar um efeito coordenador na ação, pois da resposta afirmativa do destinatário a uma oferta séria resultam obrigações que se tornam relevante para as consequências da interação (HABERMAS, 2003,V1, p.36) 


\section{VOZES $_{\text {\&DÁLORO }}^{\mid}$}

Itajaí, v. 18, n. 02, jul/dez 2019

colonização do mundo da vida pelo sistema, assim a sobreposição dos valores particulares leva à sobreposição do sucesso individual diante o entendimento mútuo. Esse desengate chega ao paradoxo de que a racionalização do mundo da vida é prejudicial ao próprio mundo da vida devido ao crescimento de subsistemas cujos imperativos se voltam contra ele através da instrumentalização da razão. Essa sobrecarga sobre os processos comunicativos acaba abrindo caminho para os meios deslinguistificados assumirem cada vez mais funções e coordenar ações, ocorrendo a reificação das estruturas simbólicas do mundo da vida pelos imperativos sistêmicos. Essa colonização do mundo da vida é responsável por uma série de patologias que atingem as sociedades contemporâneas (HABERMAS, 2000).

Se os sistemas e subsistema do modelo habermasiano apresentam uma certa simplicidade, a noção de esfera pública torna-se cada vez mais abstrata. A priori, podemos compreender a esfera pública como uma rede adequada para a comunicação de conteúdo, de tomada de posição e opiniões e nela os fluxos comunicacionais são filtrados, sintetizados, a ponto de condensar em opinião pública (LOCATELLI, 2014). A origem da esfera pública burguesa não está em sua característica política, mas sim literária. Literária porque a crítica não se dirigia aos rumos políticos da sociedade monárquica e também porque "conserva uma certa continuidade com a esfera pública representativa da corte principesca” (HABERMAS, 2001, p. 139).

A esfera pública burguesa surge do conflito dialético de dois tipos de publicidade 4 . De um lado a publicidade das cortes feudais e de outro a publicidade crítica nascida com o iluminismo. A formação da esfera pública burguesa procura funcionar enquanto instância que controla e dá legitimidade democrática ao poder exercido pelo Estado administrativo, remontando assim a visão kantiana de uso público da razão. O pressuposto que qualquer um pode julgar uma pintura ou um livro ou uma apresentação de teatro nos salões de café representou, numa concepção crítica, a possibilidade de troca racional de argumentos. A discussão racional, enquanto forma de apropriação de manifestações culturais e artísticas, possibilitou a democratização da discussão enquanto universalidade de acesso e igualdade de participação. Por mais que a esfera pública burguesa, em suas variações, seja multiforme e variada, Habermas busca aproximar dos critérios institucionais comuns dos cafés e salões, ou seja, nesses espaços as diferenças econômicas, políticas e sociais eram esquecidas em função do melhor argumento (SILVA, 2002).

\footnotetext{
${ }^{4}$ Por publicidade entende-se, aqui, publicação, o acto de tornar público algo: dar a conhecer opiniões, ideias, factos, situações ou até mesmo pessoas (aquele que publicita, ou aquele que é objecto de publicação). É nesse sentido que Kant se refere à publicidade, atribuindo-Ihe a função de mediação moral da política, sem chegar, contudo, a encará-la propriamente como uma forma de comunicação; mas é, precisamente, como uma forma de comunicação pública que dá visibilidade à política, para os participantes do espaço público em geral, e, mais importante ainda, é ela que permite projectar e dimensionar a política de acordo com as exigências, expectativas e aspirações desses mesmos sujeitos (cidadãos) (ESTEVES, 2011, p. 190).
} 


\section{VOZES $_{\text {\&IÁLORO }}^{\mid}$}

Itajaí, v. 18, n. 02, jul/dez 2019

A definição de esfera pública não é direta, não constitui uma normativa capaz de diferenciar entre competências e nem regula/produz um sistema. Como dito, não abriga um único público e nem seus públicos são iguais, é uma engrenagem social que busca soluções coletivas publicamente discutida, formulada e deliberada que façam valer os interesses da sociedade civil em contraste com as pressões do Estado (GOMES, 2008).

A partir do processo do debate público, aberto, racional e de interesse público, espera-se que exista uma posição relativamente consensual, ao qual pode-se denominá-la de opinião pública. O processo de opinião no interior dos públicos possui características muito específicas:

É um processo agonístico, no sentido em que põe em jogo (em confronto) uma diversidade de opiniões sobre um dado assunto; abre-se também, assim à livre participação individual dos membros do público para a construção da tal opinião de ordem superior vinculativa. Mas é também uma comunicação argumentativa, o que significa uma qualificação muito própria do tipo de agonística simbólica em cena nos públicos: as diferenças de opinião devem ser dirimidas através de argumentos, isto é, da apresentação de razões capazes de produzir convencimento. Aquilo que pode ser designado como opinião dos públicos (sobre um dado assunto ou problema) é, portanto algo que foi objeto de uma certa consensualização por parte dos participantes nas discussões, numa base essencial da racionalidade (ESTEVES, 2011, p $155)$.

Na democracia moderna a opinião pública tornou-se um meio de legitimação de ação do poder, transformando-se em estratégia de políticas de opinião. O campo da comunicação assumiu importância estratégica e a política de opinião precisa ser feita na esfera de visibilidade pública dominante para que o público pense de uma forma sobre determinado assunto (GOMES, 2000). A esfera de visibilidade pública tem um papel relevante para a vida democrática contemporânea porque é nela que os cidadãos terão acesso das questões que dizem respeito ao coletivo e a partir disso tomar posição sobre o poder político. Na sociedade de massas é a mídia que estabelece, na maioria das vezes, a mediação entre esfera civil e esfera política, adquirindo progressivamente uma importância central no modelo democrático representativo.

\section{Educação em cena}

Como já dito, a Educação torna-se um dos assuntos essenciais no âmbito da esfera pública. Entende-se por educação toda ação exercida pelos adultos sobre as crianças e jovens, para que esses adquiram condições exigíveis para viver em sociedade (DURKHEIM, 2011). Procurando explicar os mecanismos orientadores do funcionamento da sociedade, Durkheim (2011) apresentou os imperativos necessários 


\section{VOZES $_{\text {\&IÁLORO }}^{\mid}$}

Itajaí, v. 18, n. 02, jul/dez 2019

para sua manutenção e equilíbrio. A harmonia do corpo social como um todo dependerá da sincronia das partes, seu funcionamento estaria dependente do acato dos seus integrantes aos conjuntos de normas, leis e tradições que constituem a cultura do grupo social. Tal percepção já apresenta o papel atribuído à educação enquanto agente promotor da ordem, do progresso e da harmonia social. A educação, dentro dessa perspectiva, é um instrumento de vital importância no processo de internalização de regras, normas, símbolos e padrões de comportamento que garantam a convivência social. Quanto mais a sociedade se complexifica, mais funções especializadas vão surgindo e a educação é vista como baluarte para a preparação das novas gerações. Na modernidade a expressão máxima e formal que a educação terá é no ambiente escolar que, amparada pelo Estado, deve formar indivíduos que valorizem a razão, ciência e a moral democrática moderna. A respeito da relação Educação e Estado, Durkheim (2011, p. 63) nos alerta:

Uma vez que a educação é uma função essencialmente social, o Estado não pode se desinteressar dela. Pelo contrário, tudo o que é educação deve ser, em certa medida, submetido à sua ação. Isso não significa, no entanto, que ele deve necessariamente monopolizar o ensino. (...) Porém, o fato de o Estado dever, em prol do interesse público, autorizar o funcionamento de outras escolas além daquelas sob sua responsabilidade direta não implica que ele permaneça indiferente ao que acontece dentro dessas instituições. (...) Não há escola que possa reivindicar o direito de dar, com toda liberdade, uma Educação antissocial.

Em uma visão crítica aos pressupostos funcionalistas, é possível reconhecer que a educação formal reproduz as estruturas sociais e a transferência de capitais de forma geracional. A escola ao ignorar as diferenças de acesso do capital cultural acaba marginalizando os menos favorecidos, considerando-os incapazes de prosseguir ou estar em determinados espaços (BOURDIEU, 1998). Portanto, pode-se pensar que normativamente o surgimento da escola esteja amparado na necessidade de ter um espaço próprio para a realização de processos de caráter imanente, fomentando mecanismos de ordem psicossocial. O espaço escolar deveria ser propício para o desenvolvimento da subjetividade (LOBROT, 1992).

É possível ainda pensar em uma educação baseada num pensamento rigoroso, de razão crítica e principalmente de uma racionalidade ética que evite a barbárie, como a de Auschwitz. O mundo administrado pela racionalidade instrumental produz uma sociabilidade reprodutora de tais mecanismos, onde a visão pragmática de educação negligencia a necessidade de vínculos para pensar sobre a crise da formação cultural (ADORNO, 1995). 


\section{VOZES $_{\text {\&IÁLORO }}^{\mid}$}

Itajaí, v. 18, n. 02, jul/dez 2019

Seja por seus aspectos objetivos e sociais ou subjetivos e emancipatórios, a educação deve ser conduzida com políticas públicas do Estado capaz de abarcar integralmente a formação do educando.

No Brasil, o processo de redemocratização trouxe esperanças de mudanças, sobretudo na precária educação pública. No entanto, o período de redemocratização representou a disputa de dois processos de aberturas divergentes. Um de forças populares na busca de direitos e participação política e outro na ânsia de manter a ordem vigente, buscou consolidar um regime democrático formal que mantivesse o status daqueles que historicamente sempre se privilegiaram da estratificação social brasileira. A abertura democrática buscou restringir o impacto das forças sociais e reduzir seu espaço político, protegendo o paternalismo elitista por via do ritualismo eleitoral (FERNANDES, 1980). As disputas de projetos educacionais vão se evidenciar e acirrar-se desde a elaboração da nova Constituição Federal e se estender por quase dez anos, com a tramitação da Lei de Diretrizes e Bases da Educação Nacional (LDB) que foi concluída em 1996 (ARANHA, 2005).

No entanto, o Brasil tendeu a seguir políticas educativas importadas das agências internacionais visando, sobretudo, os anseios do mercado de trabalho. Assim, os governos democráticos de 1990 apoiaram-se em modelos neoconservadores. Para os governos, inspirados por ideias de flexibilização econômica, a educação básica torna-se fomentadora de conhecimento técnico científico dentro do paradigma neoliberal (FRIGOTTO e CIAVATTA, 2003).

No início do século XXI a chegada do presidente Lula por um partido com base popular gerou expectativa quanto ao rompimento dessa lógica neoconservadora. Ao analisar a primeira década do século XXI, Frigotto (2011), reconhece que a chegada do presidente Lula será marcada pela continuidade, sobretudo de conciliar uma minoria prepotente a uma maioria desvalida, mediante o combate da desigualdade. Ao não disputar um projeto societário antagônico ao capitalismo dependente e centrando o foco desenvolvimentista de consumo e frágil redistribuição de renda, o governo também não disputou um projeto educacional antagônico, na forma, no conteúdo e no método. A junção da fragmentação ao abandono do campo crítico na disputa de um projeto educativo, fez com que a política petista se centrasse apenas na melhoria, mediante parcerias público e privado, e atendimento da grande massa desorganizada e despolitizada. Em vez de o Estado alargar o fundo público na perspectiva de políticas públicas de caráter universal, acaba fragmentando ações em políticas focais que amenizam os efeitos, sem alterar as determinações.

Dentre as continuidades e descontinuidades, é justamente no primeiro ano de mandato do presidente Lula que o movimento Escola Sem Partido tem origem. Segundo seu fundador, o procurador do Estado de São Paulo, Miguel Nagib, naquele ano uma de suas filhas chegou da escola contando que um professor de história comparou Che 


\section{VOZES $_{\text {\&IÁLORO }}^{\mid}$}

Itajaí, v. 18, n. 02, jul/dez 2019

Guevara a São Francisco de Assis. A comparação é que ambos abriram mão de tudo por uma ideologia, um pela ideologia política outra pela religiosa. Católico fervoroso, Nagib ficou indignado com tal comparação, alegando uma tentativa de santificar o revolucionário argentino. $\mathrm{Na}$ época, escreveu uma carta aberta ao professor, imprimiu 300 cópias e distribuiu no estacionamento da escola, no entanto a recepção de sua crítica não foi das melhores, mas tornou-se mote para que no ano seguinte formalizasse o movimento Escola Sem Partido (BENDINELLI, 2016).

Segundo o site oficial do movimento, a iniciativa é conjunta de estudantes e pais preocupados com o grau de contaminação político-ideológica das escolas brasileiras em todos os níveis. Sob o pretexto de transmitir aos alunos uma visão crítica, na verdade os professores seriam um exército organizado de militantes cuja liberdade de cátedra tornouse uma cortina para os professores imporem sua própria visão de mundo. Ainda no site é possível encontrar diversas críticas ao modelo educacional vigente, bem como crítica às ideias de Paulo Freire, classificado como doutrinador. Há também inúmeros ataques a respeito dos livros didáticos, às provas de concurso público bem como às provas do Exame Nacional do Ensino Médio (ENEM) e outros vestibulares, classificando-os como doutrinárias. O movimento defende que há um sequestro intelectual, onde o estudante desenvolve com o professor/doutrinador uma ligação afetiva. A vítima, assim como numa Síndrome de Estocolmo, muitas vezes pode negar que o sequestrador esteja errado (ESCOLA SEM PARTIDO, 2019).

No campo institucional, o primeiro Projeto de Lei apresentado em um poder legislativo assentado nesses valores foi encomendado pelo então deputado estadual fluminense Flávio Bolsonaro a Miguel Nagib. O projeto de Flávio Bolsonaro foi então disponibilizado no site do Movimento como modelo para a esfera estadual e outro anteprojeto similar foi disponibilizado para a esfera municipal. Atualmente a área de projetos de lei no site do movimento foi desvinculada, transformada em um site específico e houve uma reformulação de seus conteúdos: enquanto o primeiro projeto falava da questão da moralidade e da doutrinação política, o novo anteprojeto faz menção à questão de gênero e sexualidade (MOURA, 2016).

Em nível federal, o primeiro Projeto de Lei propondo a instituição do Programa Escola Sem Partido foi o de número 867, de 23 de março de 2015, apresentado pelo deputado Izalci Lucas (PSDB). Porém, devido às afinidades de ideias, esse foi apensado ao projeto de Lei no 7.180 , apresentado no dia 24 de fevereiro de 2014, pelo deputado Erivelton Santana, que procurava alterar artigos da LDB/96, incluindo a necessidade de respeitar as convicções do aluno e de seus pais ou responsáveis, tendo os valores de ordem familiar precedência sobre a educação escolar nos assuntos relacionados à educação moral, sexual e religiosa (CÂMARA DOS DEPUTADOS, 2014). Em 2016 é constituída a comissão especial e o projeto é encaminhado para a Coordenação de Comissões Permanentes, tornando-se o momento de maior repercussão a respeito do tema. 


\title{
VOZES $_{\text {\&IÁLORO }}^{\mid}$
}

Itajaí, v. 18, n. 02, jul/dez 2019

\section{As políticas/linhas editoriais}

\begin{abstract}
Os editoriais podem dizer muito sobre a cobertura informativa da empresa de comunicação, que chega a um público mais amplo. Quais são as influências da opinião da instituição sobre a cobertura noticiosa é algo a ser investigado com maior profundidade. No entanto, os editoriais passam por um dilema ainda maior, pois não podem se utilizar de estratégias como a objetividade para justificar os enquadramentos apresentados, obrigando o jornal a trazer para si a responsabilidade das caracterizações e das opiniões em foco, ao invés de atribuí-las a uma suposta reflexão da realidade (MONT'ALVERDE; JAMIL MARQUES, 2018, p. 32)
\end{abstract}

O Editorial é o gênero jornalístico que vai expressar a opinião oficial da empresa diante os acontecimentos de maior repercussão ou importância social do momento. Os editoriais refletem os consensos que emanam dos diferentes núcleos que participam da propriedade e organização do jornal. Normativamente em uma sociedade que possuí uma opinião pública autônoma com uma sociedade civil forte, o editorial é direcionado para a orientação dessa opinião pública. O que não é o caso do Brasil, no Brasil o editorial dirigese formalmente para a opinião pública, mas encerra uma relação de diálogo com o Estado. Um diálogo de coação para a defesa de interesses dos segmentos empresariais e financeiros que representam (MARQUES DE MELO, 2003).

Uma vez que representa a voz da empresa, o editorial busca a impessoalidade na abordagem temática e nas estratégias de argumentação. É no editorial que o jornal sai da condição de imparcialidade, assumindo ter posições sobre temas que concernem a vida pública. A leitura dos editoriais ajuda na compreensão do que as instituições jornalísticas pretendem dizer, coagir, os dirigentes do Estado de qual maneira gostariam de orientar os assuntos públicos (MARQUES MELO, 2003). O editorial é também um instrumento que colabora os jornalistas a orientar seu olhar e guiar seus trabalhados no jornal.

Percebe-se que o editorial é uma fonte importante para compreender e situar o veículo de comunicação sobre diversos acontecimentos sociais frente aos quais o grupo se posiciona, pois é ali manifestado sua opinião sobre acontecimentos pertinentes e de interesse coletivo. Os editoriais vistos como conselheiros ou guias dos leitores dizem muito sobre o que os próprios jornais acreditam cumprir na realidade em que estão circunscritos. 


\section{VOZES $_{\text {\&IÁLORO }}^{\mid}$}

Itajaí, v. 18, n. 02, jul/dez 2019

\section{Organizando a análise}

Para fins analíticos, a adaptação ocorre sobre a interpretação socioteórica de análise crítica do discurso desenvolvida por Norman Fairclough (2001). Por discurso compreendese um modo de ação, permitindo às pessoas agirem sobre o momento, construindo o mundo com significado. A prática discursiva entende o texto dentro de uma interdiscursividade, necessitando compreender o texto dentro da contextualização histórica, política e ideológica na qual está inserido.

Dada a delicadeza do assunto, envolvendo uma das áreas centrais da vida humana, bem como do uso constante do termo, faz-se necessário uma pequena consideração sobre ideologia. Diferentemente de algumas décadas atrás que se pensava alternativas ao capitalismo liberal, hoje o capitalismo tornou-se o "real”, ou seja, há uma "ideologia qua matriz geradora que regula a relação entre o visível e o invisível, o imaginável e inimaginável, bem como as mudanças nessa relação” (ZIZEK, 1999, p. 07). É possível detectar três momentos da ideologia, a ideologia "em si”, "para si” e processo heterogêneo.

A ideologia "em si” é vista como um conjunto de crenças cujo objetivo é convencer as classes sociais de sua veracidade, mas na prática servindo algum interesse de poder. Momento em que a ideologia pode ser vista como aquela que faz com que as classes sociais naturalizem suas condições de vida, julgando-as como corretas e justas. A segunda maneira de compreender a ideologia é pela sua existência material, ou 'para si” onde a ideologia é compreendida pelo seu caráter externo, constituída por rituais ideológicos e fomentada pelos Aparelhos Ideológicos do Estado. Por fim, a compreensão da ideologia como processo heterogêneo, deixa de entendê-la como um cimento que garante a reprodução social, mas como atitudes "espontâneas" ou "não ideológicas". A coerção extra ideológica do mercado, por exemplo, é ideológica por excelência (ZIZEK, 1999). A ideologia não seria uma mera falsa consciência, mas "uma realidade social cuja a própria existência implica o não conhecimento de sua essência por parte de seus participantes" (ZIZEK, 1999, p.306). O núcleo da ideologia "não é de uma ilusão que mascara o verdadeiro estado de coisas, mas de uma fantasia (inconsciente) que estrutura nossa própria realidade social” (1999, p. 316).

Predominantemente, a discussão acerca da ideologia parte de três características: sua existência material, a interpelação feita aos sujeitos e os aparelhos ideológicos. Ao dar ênfase na transformação através da remodelação de práticas discursivas, as ideologias constituídas nelas contribuem para modificar as relações de dominação. Fairclough (2001, p.117), compreende ideologia como:

Significações/construções da realidade (o mundo físico, as relações sociais, as identidades sociais) que são construídas em várias dimensões das formas/sentidos das práticas discursivas e que contribuem para a 


\section{VOZES $_{\text {\&DÁLORO }}^{\mid}$}

Itajaí, v. 18, n. 02, jul/dez 2019

produção, a reprodução ou a transformação das relações de dominação. (...) As ideologias embutidas nas práticas discursivas são muito eficazes quando se tornam naturalizadas e atingem o status de "senso comum";

Por fim, pode-se compreender a ideologia com sendo sustentada e mobilizada pelas formas simbólicas que estão servindo e sustentando as relações de dominação. Assim, a reprodução da dominação se dá pelo processo contínuo de produção e recepção de formas simbólicas. Por forma simbólica é compreendido como um "amplo espectro de ações e falas, imagens e textos, que são produzidos por sujeitos e reconhecido por eles e outros como construtos significativos" (THOMPSON, 2011, p. 79).

Buscando princípios de organização e análise do objeto empírico, o enquadramento (MAIA, 2009) colabora na compreensão dos Editoriais e dos acontecimentos sociais circunscritos no texto, gerando esquemas interpretativos no processo de estruturação de sentido, relacionando com a dinâmica social. $\mathrm{O}$ enquadramento colabora com a compreensão dos meios de comunicação na produção de visibilidade dos atores e seus discursos.

O levantamento material foi empreendido por pesquisa analógica, cujo critério foi a seleção do primeiro texto editorial cujo tema central fosse as atividades empreendidas pelo movimento Escola Sem Partido a partir do ano de 2014, ano de formalização de projeto de Lei no Congresso. Os três jornais apresentaram o editorial somente no ano de 2016, a partir da constituição da Comissão Especial na Câmara de Deputados. Somado a isso a forte turbulência política ao qual o país passava, sobretudo com o crescimento do antipetismo. A tabela abaixo representa elementos centrais de cada texto.

Tabela 1: Elementos centrais em cada texto analisado

\begin{tabular}{|l|l|l|l|}
\hline Jornais & Estado de S. Paulo & Folha de S. Paulo & O Globo \\
\hline Título do editorial & Ideologia na Escola & Na base da Ideologia & Um ensino Livre \\
\hline Data de Publicação & $19 / 07 / 2016$ & $15 / 05 / 2016$ & $15 / 07 / 2016$ \\
\hline
\end{tabular}




\section{VOZES ${ }_{\text {ÉDIÁLOGO }}^{\mid}$}

Itajaí, v. 18, n. O2, jul/dez 2019

\begin{tabular}{|c|c|c|c|}
\hline Primeira Oração & $\begin{array}{l}\text { “Evidências não faltam } \\
\text { de que muitos } \\
\text { professores têm } \\
\text { transformado as salas } \\
\text { de aula em laboratório } \\
\text { de ideologia } \\
\text { esquerdista, sob o } \\
\text { argumento de que é } \\
\text { necessário criar } \\
\text { 'resistência' a uma } \\
\text { suposta onda } \\
\text { conservadora." }\end{array}$ & $\begin{array}{l}\text { "A educação pública } \\
\text { no Brasil padece de } \\
\text { muitos males, a } \\
\text { começar por sua } \\
\text { ineficiência na missão } \\
\text { de dar aos alunos } \\
\text { domínio da língua e } \\
\text { da matemática." }\end{array}$ & $\begin{array}{l}\text { "Mais do que senso } \\
\text { comum, a laicidade } \\
\text { do Estado é um } \\
\text { princípio assegurado } \\
\text { pela Constituição } \\
\text { brasileira." }\end{array}$ \\
\hline $\begin{array}{l}\text { Posição sobre o } \\
\text { projeto de Lei } \\
\text { defendido pelo Escola } \\
\text { Sem Partido }\end{array}$ & $\begin{array}{l}\text { Contrário ao projeto. } \\
\text { Flerta com o } \\
\text { autoritarismo. }\end{array}$ & $\begin{array}{l}\text { Contrário ao projeto. } \\
\text { Autoritarismo e } \\
\text { contradiz com a } \\
\text { orientação liberal que } \\
\text { diz inspirá-la. }\end{array}$ & $\begin{array}{l}\text { Contrário ao projeto. } \\
\text { Impor Index é } \\
\text { perigoso. Educação } \\
\text { livre não comporta } \\
\text { totalitarismo. }\end{array}$ \\
\hline $\begin{array}{l}\text { Posição sobre as } \\
\text { denúncias } \\
\text { empreendidas pelo } \\
\text { Escola Sem Partido }\end{array}$ & $\begin{array}{l}\text { Concorda com a } \\
\text { existência de } \\
\text { doutrinação } \\
\text { esquerdista. } \\
\text { Reconhece que o } \\
\text { movimento como } \\
\text { conservador. }\end{array}$ & $\begin{array}{l}\text { Concorda com a } \\
\text { existência de uma } \\
\text { doutrina esquerdista. }\end{array}$ & $\begin{array}{l}\text { Concorda com a } \\
\text { existência de uma } \\
\text { realidade educacional } \\
\text { influenciada pelo } \\
\text { sectarismo ideológico }\end{array}$ \\
\hline
\end{tabular}




\section{VOZES $_{\text {\&DÁLORO }}^{\mid}$}

Itajaí, v. 18, n. 02, jul/dez 2019

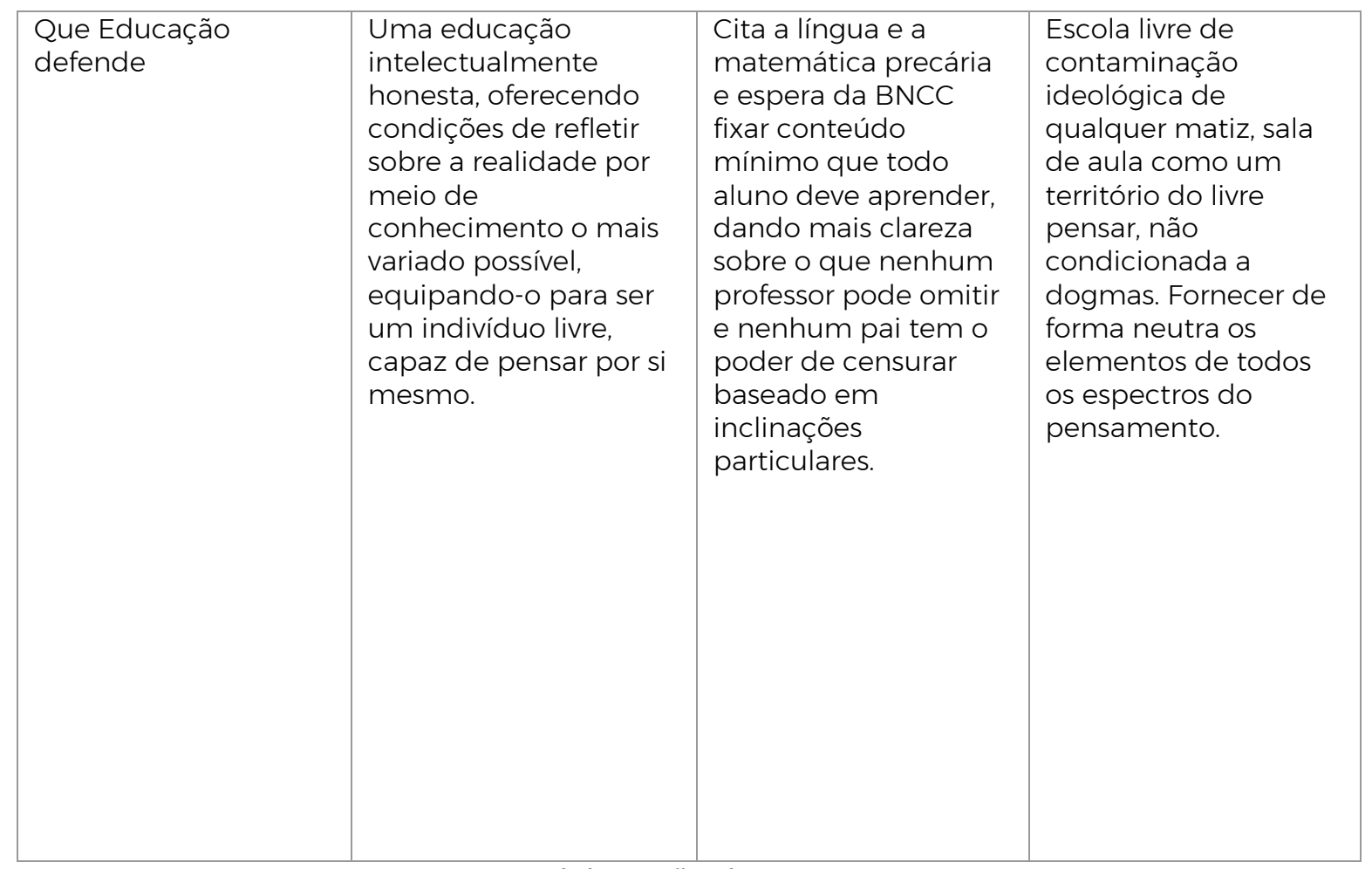

Fonte: elaboração dos autores

Os três editoriais apresentam dois consensos interessantes: Acreditam na doutrinação da educação brasileira, mas são contra as medidas propostas pelo movimento Escola Sem Partido, por flertar com autoritarismo. O jornal Estado de São Paulo e Folha de São Paulo foram mais enfáticos no argumento da doutrinação esquerdista, termo não usado pelo jornal O Globo. No entanto o jornal O Globo fala em contaminação ideológica, termo usado no site oficial do movimento ESP.

Pode-se extrair questões pertinentes no direcionamento dos três jornais: A naturalização de uma percepção de Educação neutra ou "não ideológica", bem como a busca de objetividade onde ideologia é a percepção do Outro. Há uma simplificação da ideologia (do outro) como se ela fosse uma distorção e o Real fosse descrito nas linhas do jornal $^{5}$. Ao não contextualizar a ambivalência e complexidade do termo, os editoriais se encaixam nesse processo ideológico quando disseminam o "real" contra o "falso" ou o "neutro" contra a "doutrina”. Dissimulam o real porque partem da ideia que a estrutura e

\footnotetext{
${ }^{5} \mathrm{~A}$ isso Wilson Gomes chama de realismo ingênuo, afinal, "o conhecimento não é simplesmente percepção e consciência de algo, do objeto; a percepção e o conhecimento mesmo e todo o âmbito do co-presente fazem parte do objeto da percepção e do conhecimento. O fato conhecido, portanto, é bem mais do que aquilo que na natureza seria disponível, porque inclui, para além do que é objetivamente dado, a visitação do desejo e dos temores, o repertório e a gramática das imagens e das figuras do imaginário que são nossas ou vis (violência e virtude) semântica e sintática da língua e do conhecimento, dentre outras coisas. Conhecer, portanto, está muito longe de ser um mero registro de dados e objetivos disponíveis (GOMES, 2009, p 23).
} 


\section{VOZES $_{\text {\&IÁLORO }}^{\mid}$}

Itajaí, v. 18, n. 02, jul/dez 2019

as relações sociais são naturais, ignorando a constituição histórica na conformação do arranjo social. Nesse caso a aposta de Zizek de que o mercado e os meios de comunicação de massa estão dialeticamente interligados, onde "a mídia estrutura antecipadamente nossa percepção da realidade" (1999, p.21) tornando indiscernível de sua imagem "estetizada" faz bastante sentido. Ao atacarem a "ideologia esquerdista" ou exigirem uma educação neutra, os próprios editoriais operam como se tivessem posse sobre o real.

O jornal $O$ Estado de $S$. Paulo ao menos reconhece que a ideologia do movimento ESP é conservadora, mas considera legítimas as denúncias empreendidas pelo grupo. Aposta em uma educação em que é oferecido aos alunos variadas maneiras de compreender a realidade (que já está previsto na LDB/1996), formando um indivíduo livre capaz de pensar por si mesmo. Essa percepção de indivíduo autônomo encarna o espírito liberal clássico, que não deixa de ser uma percepção ideológica de mundo.

A Folha de S. Paulo começa denunciando as deficiências básicas da educação brasileira, no entanto ressaltando apenas duas dimensões disciplinares da educação: língua e matemática. Acredita na predominância da cultura "esquerdista" entre os educadores, ressaltando as denúncias feito pelo movimento ESP. Realça o espírito liberal do jornal (apesar de, outrora, ter chamado a Ditadura Militar de Ditabranda) ao denunciar a contradição do ESP ao querer leis primitivas de Estado e, por fim, aposta na Base Nacional Curricular Comum como uma saída para fixar o que os professores devem ou não devem passar.

O Globo, por sua vez, realça o Estado democrático de direito, bem como na autodeterminação do indivíduo. A escola deve estar livre de contaminação ideológica e a sala de aula, território do livre pensar. Apesar de não usar a palavra esquerdista, denuncia o sectarismo e o proselitismo na realidade educacional, depositando a confiança em um ensino neutro.

\section{Visibilidade comprometida?}

Ancorado no processo comunicativo como fundamento na política democrática, a concepção deliberacionista procura superar as teorias que limitavam a democracia à agregação de interesses. A teoria deliberativa parte do pressuposto que as soluções que afetam a coletividade devem ser alvo de justificação pública legitimada pela cooperação argumentativa entre os atores sociais. Essa noção de democracia aposta numa comunicação ideal onde as discussões públicas são inclusivas, baseadas na sinceridade de que o melhor argumento, e não qualquer outro tipo de coação, é que garante a tomada de decisão (SILVA, 2002).

No entanto algumas ponderações a respeito dessa aposta devem ser feitas. Reconhecendo a importância editorial na atividade jornalística, os editoriais analisados 


\title{
VOZES $_{\text {\&IÁLOGO }}^{\mid}$
}

Itajaí, v. 18, n. 02, jul/dez 2019

discorreram com uma pretensa neutralidade e objetividade, ignorando toda a complexidade trazida pelo tema. Mesmo com divergências pontuais, Zizek (1999), Fairclough (2001) e Thompson (2011) percebem que a ideologia opera na justificativa e naturalização das relações de dominação existente. Nenhum jornal citou, por exemplo, o problema histórico e estrutural da educação brasileira, muito menos o contexto socioeconômico que obriga muitos estudantes a abandonarem os bancos escolares.

Comprovado a harmonia política dos editoriais, e partindo de uma leitura crítica ao deliberacionismo, organizadas por Luis Felipe Miguel (2014a), deve-se reconhecer que as assimetrias sociais na produção de competências discursivas comprometem a construção de consensos. Ignorando as desigualdades materiais e apostando que a esfera pública opera pela igualdade abstrata do campo jurídico e político, o deliberacionismo aproxima-se muito da ideia liberal. Somado a isso, a aposta dialógica face a face, típica do exercício socrático, torna-se insustentável nas democracias contemporâneas, necessitando a mediação dos meios de comunicação de massa.

Ora, se as apostas deliberacionistas dependem fortemente da visibilidade para o processo de discutibilidade e, a respeito desse tema, esses três jornais operam de maneira muito próxima, qual a qualidade e direcionamento a discutibilidade terá na tomada de decisões? Qual é a garantia substancial que a discutibilidade propiciará os melhores argumentos e consensos? Quais outros jornais, com tamanha estrutura e visibilidade, divergem das naturalizações feita pelos três jornais?

Ainda segundo Miguel (2014a) os consensos tendem a negar o caráter conflitivo da política. Nessa prerrogativa entende a política através do dissenso porque rompe com "a evidência sensível da ordem natural que destina os indivíduos e os grupos ao comando e à obediência, (...) a certa maneira de ser, de ver e dizer” (RANCIÈRE, 2010, p 86).

\begin{abstract}
O sentimento de impotência diante de forças que não se pode controlar, o temor de ser alvo de medidas punitivas, a privação dos recursos necessários para orientar a própria vida na direção desejada: essas não são circunstâncias excepcionais, mas o núcleo da experiência vivida de milhões de pessoas. Nesse cenário, é difícil vislumbrar a produção de um consenso autêntico sobre as regras do jogo ou, a fortiori, sobre "valores ético-políticos" de base. A concordância, mesmo que voluntária, não implica equilíbrio na capacidade de influência, nem na ausência de relações de dominação (MIGUEL, 2014b, p. 37).
\end{abstract}

Nenhum dos editoriais citou o grande desconforto e críticas dos educadores a respeito do tema. O simplismo consensual dos jornais estimula uma visibilidade que direciona a opinião pública a caminhos obscurantistas. Não por acaso, o atual presidente da República reitera os ataques denunciado pelo movimento Escola Sem Partido (reconhecido como existentes pelos três jornais). Vai ver os problemas da educação 


\section{VOZES $_{\text {\&IÁLORO }}^{\mid}$}

Itajaí, v. 18, n. 02, jul/dez 2019

brasileira seja culpa dos doutrinadores e não, como diria Darcy Ribeiro, um projeto político.

\section{Referências}

ADORNO, T.W. Educação e Emancipação. Rio de Janeiro: Paz e Terra, 1995.

ARANHA, M. L. História da Educação. São Paulo: Moderna, 2005.

BEDINELLI, T (2016). "O professor da minha filha comparou Che Guevara a São Francisco de Assis”. El País, Edição Brasil, online, 25 jun. Acesso em: Maio de 2018.

BOURDIEU, P. Escritos de Educação. Petrópolis: Vozes, 1998

DURKHEIM, E. Educação e Sociologia. Petrópolis: Vozes, 2011

ESCOLA SEM PARTIDO. Programa Escola sem Partido: 2019. Disponível em https://www.programaescolasempartido.org ; Acesso em: Junho de 2019.

ESTEVES, J. Espaço público e democracia: comunicação, processo de sentido e identidade social. São Leopoldo: Ed. Unisinos, 2003.

FAIRCLOUGH, Norman. Discurso e mudança social. Brasília: Editora Universidade de Brasília, 2001.

FERNANDES, F. Brasil em compasso de espera: pequenos escritos políticos. São Paulo: Editora Hucitec, 1980.

FOLHA DE SÃO PAULO. Na base da Ideologia. São Paulo: Grupo Folha, 15/05/2016. Disponível em <https://wwwl.folha.uol.com.br/opiniao/2016/05/1771333-na-base-daideologia.shtml>

FREITAG, B. "Habermas e a Teoria da Modernidade", Cadernos CRH, No 22, Jan. Jun. de 1995.

FRIGOTTO, G; CIAVATTA, M. Educação básica no Brasil na década de 1990: subordinação ativa e consentida à lógica de mercado. In: Educação e sociedade, v.24, $\mathrm{n}^{\mathrm{O}}$ 82. Campinas-SP: abril de 2003.

FRIGOTTO, G. Os circuitos da história e o balanço da educação no Brasil na primeira década do século XXI. In: Revista Brasileira de Educação, vol. 16, n. 46, jan./abr. 2011.

GOMES, W. Opinião pública política hoje. In: IX Encontro Anual da Associação Nacional dos Programas de Pós-Graduação em Comunicação. Porto Alegre: 2000

GOMES, W. Da discussão a esfera pública. In: GOMES, W.; MAIA, R.C. Comunicação e democracia: problemas e perspectiva. São Paulo: Paulus, 2008. 


\section{VOZES \\ DIÁLOGO}

Itajaí, v. 18, n. 02, jul/dez 2019

GOMES, W. Jornalismo, Fatos e interesses: Ensaios de teoria do jornalismo. Florianópolis: Insular, 2009.

HABERMAS, J. O discurso filosófico da modernidade. São Paulo: Martins Fontes: 2000.

HABERMAS, J. Direito e democracia: entre facticidade e validade. Vol I. Rio de Janeiro: Tempo Brasileiro, 2003.

HABERMAS, J. Mudança estrutural da esfera pública. São Paulo: UNESP, 2001.

LOBROT, M. Para que serve a escola? Lisboa: Terramar,1992.

LOCATELLI, C A. Comunicação e Barragens: o poder da comunicação das organizações e das mídias na implantação de hidrelétricas. Florianópolis: Insular, 2014.

MAIA, R. Debates públicos na mídia: enquadramentos e troca pública de razões. In: Revista Brasileira de Ciência Política. nº 2 - Brasília, julho/dezembro de 2009

MIGUEL, L. F. Deliberacionismo e os limites da crítica: uma resposta. Opinião Pública, Campinas, v. 20, n. 1, p. 118-131, abr. 2014a.

MIGUEL, L. F. Consenso e conflito na teoria democrática: para além do agonismo”. Lua Nova, São Paulo, 2014b.

MONT'ALVERDE, C; JAMIL MARQUES, F.P. A opinião da empresa no jornalismo brasileiro: Um estudo sobre a função e a influência política dos editoriais. In: JAMIL MARQUES, F. P; CERVI, E. U; MONT'AlVERDE, C.; CARVALHO, F. C(Org.). Estudos sobre Jornalismo Político. Curitiba: CPOP-UFPR, 2018.

O ESTAdO DE SÃO PAUlO. Ideologia na Escola. São Paulo: Grupo Estado, 19/07/2016. Disponível em: <https://opiniao.estadao.com.br/noticias/geral,ideologia-naescola, $10000063694>$

O GLOBO. O risco do pensamento totalitário. Rio de Janeiro: Organizações Globo, 20/07/2017. Disponível em: <https://oglobo.globo.com/opiniao/o-risco-do-pensamentototalitario-na-educacao-19748541>

PAIXÃO MARCOS, P. Linha editorial no jornalismo brasileiro: conceito, gênese e contradições entre a teoria e a prática. Revista Alterjor, v. 17, n. 1, p. 90-108, 15 jan. 2018.

PIZZI, J. O mundo da vida: Husserl e Habermas. Ijuí: Editora Unijuí, 2006.

RANCIÈRE, J. O Desentendimento: política e filosofia. São Paulo: Editora 34, 1996.

SILVA, F. C. da. Espaço Público em Habermas. Lisboa: Instituto de Ciências Sociais, 2000 . 